\title{
Users Divided? Exploring the Gender Gap in Internet Use
}

\author{
LINDSAY H. SHAW ${ }^{1}$ and LARRY M. GANT, Ph.D. ${ }^{2}$
}

\begin{abstract}
Many believe that males and females use and regard computer technology differently. Males are generally assumed to be more comfortable with, more adaptable to, and less anxious with computer technology. The same biases are now being applied specifically to Internet technology. Based on research showing that men prefer to use the Internet for information gathering and entertainment, while women prefer to use the Internet for interpersonal communication, this study examined the effects of Internet use when both males and females engaged in the same activity. Participants engaged in synchronous, dyadic chat sessions, and changes in repeated measures of loneliness, depression, self-esteem, and perceived social support were tracked over time. Although previous studies have concluded not only that males and females differ in their computer cognitions and attitudes, but also that they differ in the types of applications they pursue online, no gender differences were found in the present study.
\end{abstract}

\section{INTRODUCTION}

$\mathbf{I}^{\mathrm{T}}$ T HAS BEEN ASSUMED WIDELY, and often validated empirically, that women and men differ in their attitudes toward, comfort with, and anxiety regarding computer technology. ${ }^{1-3} \mathrm{Re}-$ cently, as more people gain access to the Internet, researchers have begun to investigate whether similar gender differences exist with Internet technology. Although most researchers are quick to point out that the evidence for specific gender differences in computer cognitions and usage is conflicting and inconclusive, a widespread belief that computers, and now the Internet, are male-biased technologies still persists. ${ }^{4}$

Based on this assumption, researchers tend to predict that males and females will differ fundamentally in the ways they view and use the Internet, hypothesizing that men will be more comfortable with and less anxious about Internet technology. They have proposed a variety of explanations for these predictions, often focusing on technophobia-the idea that females are more afraid of technology and therefore slower to adapt to technological advances-and the enduring male bias in computer technology in general (for example, computer game designers targeting their products primarily towards males), which might deter females from exploring and embracing the Internet.1,5 Indeed, some studies have found that males report more experience using the Internet. ${ }^{5}$ They also score higher on measures of comfort, ${ }^{3}$ innovativeness, and Internet self-efficacy.6,7 
This apparent lack of confidence among female Internet users has not translated into a disproportionately male Internet-user population. One leading Internet monitor tracked Internet activity in December 2000 and December 2001 and found women outnumbered men online both years (50.4 million females vs. 48.2 million males in December 2000; 55.0 million females vs. 49.8 million males in December 2001). Furthermore, the female population increased $9 \%$ between the two measurement periods, whereas the male population only increased $3 \% .8$ The numbers show that, if women are intimidated by the Internet, they are nonetheless logging on in droves.

However, the same Nielsen//NetRatings study discovered that male and female users differed in the ways they accessed the Internet. Males accessed the Internet more frequently, averaging 21 log-ons in December 2001, compared to 17 for the average female user. Moreover, the male users spent an average of $11 \mathrm{~h}$ online during that period and visited 801 web pages, whereas female users only spent $9 \mathrm{~h}$ online, visiting only 573 web pages on average. ${ }^{8}$ Some researchers have found similar patterns in smaller samples as well, showing that males use computers more and access the Internet more frequently. ${ }^{5}$ For example, Odell and colleagues found that, in a sample of 843 students, males used the Internet an average of $7.1 \mathrm{~h}$ per week, versus $5.4 \mathrm{~h}$ per week among female participants. ${ }^{9}$ Other researchers, however, found no differences in frequency of Internet use. $6,7,10,11$

A more consistent pattern that has emerged in Internet research shows that males and females use the Internet for different purposes. Internet use is generally broken down into three components or motives: communication, information gathering, and entertainment. Females are most commonly associated with the communication motive, while males are linked to the information gathering and entertainment motives. Across the existing research, this pattern tends to hold up. For instance, in a study of the interaction between gender, extraversion, neuroticism, and the three motives for using the Internet, Hamburger and Ben-Artzi found that extraversion and neuroticism were linked to females' tendencies to seek out social interaction online; extraversion among males was positively correlated to the entertainment motive, while neuroticism among males was negatively correlated with information services. There were no links between males and the social motive, or between females and the information and entertainment motives. ${ }^{12}$

Supporting the notion that different motivations drive males and females to log on, data show that females tend to use email more than males, whereas males report more frequently accessing the World Wide Web.3,10 Jackson and colleagues conducted a study of 630 students and used path analyses to show that gender affects email and web use directly. ${ }^{7}$ Another study found not only that women used email more, but also that they rated email more highly on measures of how fun email is and how fun and useful the Internet is for keeping in touch with others and meeting new people. ${ }^{10}$ While there is still an overarching malebias in regards to Internet technology in terms of attitudes and cognitions, the tendency now is to compartmentalize different types of Internet use and to label them "male" or "female."

\section{EFFECTS OF INTERNET USE}

Another pervasive bias in popular and academic literature is the notion that Internet use is socially and psychologically harmful to users. Headlines such as “The Web's Dark Side in the Shadows of Cyberspace, An Ordinary Week is a Frightening Time" 13 and "Caught in the Net: How to recognize signs of Internet addiction and winning strategy for recovery"14 would lead readers to believe that the Internet is an inherently cold and dangerous technology. Empirical evidence, however, is inconclusive at best. Although the most influential study to date, Kraut and colleagues' 1998 Internet Paradox Study, positively correlated Internet use with social and psychological harm to users, much of the research published since that study have found the effects to be weak, mediated, or nonexistent. ${ }^{11}$

The crux of the social harm argument is that the Internet is essentially a solitary technology. 
This contention is based on the supposition that time spent on the Internet necessarily supplants the time that users spend establishing and nourishing "real world" relationships, thereby breaking down users' social support network. ${ }^{11,15}$ Additionally, there is an ongoing debate about whether online relationships have the potential to be as meaningful as faceto-face relationships or if they are inherently less fulfilling, as many people allege. ${ }^{6}$

Many researchers also link Internet use to negative psychological variables such as loneliness and depression. ${ }^{7}$ Some even go so far as to implicate Internet use as a causal factor for psychological harm among users.11,16 Pathological Internet use (PIU) is the new catch phrase in Internet literature, referring to the nebulous phenomenon of "Internet addiction," which is gaining credibility and popularity among researchers. ${ }^{17-19}$ The predominant assumption seems to be that the Internet is inherently detrimental to users' overall well-being.

It is primarily the Internet Paradox Study that has lent weight to the argument that the Internet affects users negatively. ${ }^{11}$ In this longitudinal study, participants' social involvement and psychological welfare were correlated with their levels of Internet use. Using selfreport measures of family communication, size of local and distant social networks, and social support, researchers discovered that Internet use was positively correlated with diminishing communication between family members in the participant households. Taking into account extroversion and larger initial local networks, researchers also found that participants who used the Internet more were likely to experience a reduction of their local and distant social networks. Furthermore, loneliness, depression, and daily stress were positively linked to greater Internet usage when researchers controlled for possible mediating variables. To bolster these findings, the researchers ran path analyses and determined that the Internet caused the observed effects. ${ }^{11}$

When the Internet Paradox Study was published, it received a lot of media coverage and helped contribute to anti-Internet sentiment. ${ }^{20}$ However, research published since has not supported the widespread notion that Internet use is dangerous or detrimental. For instance, Sanders and colleagues measured depression among high-school students, anticipating that higher levels of Internet use would be associated with increased levels of depression; they found no relationship. ${ }^{15}$ Similarly, LaRose et al. undertook to explain Kraut and colleagues' assertion that Internet use causes depressions through complex path models that took into account possible mediating and moderating variables. However, after analyzing their data, they concluded that the evidence did not corroborate earlier findings. ${ }^{21}$ LaRose and colleagues subsequently argued that the depression associated with Internet use was probably due to Internet stress (stress induced by being online-e.g., stress caused by difficulty establishing a network connection ${ }^{16}$ but that stressinduced depression was counteracted by self-efficacy. Furthermore, they found that, among certain populations, depression was allayed through interpersonal communication facilitated by the Internet. 16,21

Contrary to the idea that the Internet is a socially isolating technology, recent studies positively related the Internet to measures of social involvement. Hamburger and Ben-Artzi demonstrated that Internet use, as a function of trait variables, can decrease loneliness among users. ${ }^{12}$ Similarly, LaRose et al. found that Internet communication, particularly communication with known others via email, increased measures of social support. ${ }^{21}$ As a whole, the recent research suggests that it is necessary to reexamine the underlying assumption that has shaped Internet research, namely that Internet use is detrimental to users' social and psychological well-being. Furthermore, although gender differences have been discussed widely in reference to what leads people to log on, an examination of the ways that males and females might be affected differently by Internet use is conspicuously missing in the existing literature.

\section{OVERVIEW AND HYPOTHESIS}

The goal of the present study was to test whether Internet use would affect males and females differently when they engaged in the 
same type of Internet activity. To this end, each participant engaged in five synchronous, anonymous chat sessions with another participant. Participants completed baseline measures of depression, loneliness, self-esteem, and perceived social support. In order to assess changes in their scores over time, they completed the same measures after the second chat session and after the final chat session. Overall, the hypothesis was that scores would improve for all participants - that is, loneliness and depression would decrease, while self-esteem and perceived social support would increase. Since an interpersonal communication motive is more often associated with female Internet users, the changes in the female participants' scores over time were expected to be greater than changes in the males' scores.

\section{MATERIALS AND METHODS}

\section{Participants}

Participants were undergraduate students at the University of North Carolina at Chapel Hill who were enrolled in an introductory psychology course. Forty-six students signed up initially. Twelve males and 28 females completed the study (total $n=40$ ).

\section{Design}

Participants in this study met individually with the experimenter three times, and each engaged in five structured chat sessions with another participant, for a total of eight required interactions over the course of the study. At each of the meetings with the experimenter, participants completed the same battery of self-esteem, perceived social support, depression, and loneliness scales. Since the goal was to assess whether the chat sessions yielded changes in participants' scores over time, the interactions were scheduled in the following manner: introductory meeting, chat sessions 1 and 2, intermediate meeting, chat sessions 3, 4, and 5, and final meeting. Partner condition for the chat sessions was a between-participants variable. There were 12 male-female chatting dyads and eight female-female dyads.

\section{Measures}

Depression. Depression was measured using the Center for Epidemiological Studies Depression Scale (CES-D). ${ }^{22}$ The scale consists of 20 items relating to mood and behavior (e.g., "I was bothered by things that usually don't bother me," "I felt hopeful about the future," "I talked less than usual."). Subjects rate each statement on a four-point scale $(0=$ rarely or none of the time [less than 1 day]; $3=$ most or all of the time [5-7 days]) according to how they felt and behaved during the week prior to filling out the scale.

Loneliness. Loneliness was measured using the Revised UCLA Loneliness Scale (UCLA). ${ }^{23}$ This 20-item scale asks participants how frequently they agree with statements such as "I feel left out," "I am no longer close to anyone," and "My social relationships are superficial." Agreement is measured on a four-point scale ranging from never $(1=$ never $)$ to often $(4=$ often).

Self-esteem. Self-esteem was measured using the Texas Social Behavior Inventory (TSBI). ${ }^{24}$ The TSBI consists of 32 items relating to various aspects of one's self-concept (e.g., "I am a good mixer," "I would describe myself as indecisive," "I feel I can confidently approach and deal with anyone I meet"). Participants rated how strongly they agree or disagree with each statement on a five-point scale $(1=$ not at all characteristic of me; $5=$ very much characteristic of me).

Social support. Social support was measured using the Cohen-Hoberman Interpersonal Support Evaluation List (CHISEL). ${ }^{25}$ The scale is designed to measure how one evaluates the accessibility of social resources. CHISEL is comprised of 48 true/false items. It is broken down into four subscales, each relating to a different aspect of social support: selfesteem, appraisal, belonging, and tangible. The appraisal scale assesses whether a subject has someone in whom she or he can confide if s/he has a problem (e.g., "I don't know anyone at school or in town who makes my problems clearer and easier to understand"). The 
belonging scale measures a subject's social network (e.g., "I belong to a group at school or in town that meets regularly or does things together regularly"). The tangible scale gauges whether a subject believes that she or he can turn to someone for material aid (e.g., "I don't know anyone who would loan me several hundred dollars to pay a doctor bill or dental bill"). Each CHISEL subscale consists of 12 true/ false items.

\section{Technology}

In order to prevent users not associated with the study from entering the chat sessions, all sessions were conducted in chat rooms on a web page designed specifically for this study. The web page was maintained by the Center for Institutional Technology at UNC-CH and administered using WebChat C.T. software. Access was restricted to an experimenter and participants, who were each issued one of two valid usernames and passwords at the beginning of the study. The content of the discussions was automatically recorded and saved with the participants' permission. Only the experimenter could access the data once it was stored.

Participants were allowed to chat from any computer with Internet access, including personal computers in their homes or dorm rooms, and computers at the campus libraries. Originally, participants were not instructed to use a specific server. However, it was discovered early in the study that the chat rooms could not be accessed using Microsoft Internet Explorer. Thereafter all participants were asked to use Netscape for the duration of the experiment. Some participants also reported that they were successful in accessing the chat rooms using America Online (AOL).

\section{Procedure}

Experimental sessions were posted on a web page designed to recruit students in an introductory level psychology course at the University of North Carolina at Chapel Hill. There were no exclusion criteria. At the time of signup, students did not know the purpose of the experiment. The only information they were given was the name of the experiment ("Internet Communication"), and they were informed that the experiment required multiple sessions.

During the initial meeting with the experimenter, which each participant completed individually, participants signed informed consent forms stating that the purpose of the experiment was to "study issues of social interaction as they relate to Internet communication." Participants were advised that the experiment would consist of eight sessions (five on the Internet and three face-to-face with the experimenter) and that the study would not be explained in full until all eight sessions were completed. Once the participants understood the general design, each completed a questionnaire consisting of the CES-D, UCLA, TSBI, and CHISEL. Participants were not told what scales they were completing and were given as much time as necessary. The results of scales completed at this initial testing were used to record baseline measures of depression, loneliness, self-esteem, and perceived social support.

Upon completion of the scales, participants were asked to provide the experimenter with a schedule of their classes and extracurricular activities, in order to make it easier to schedule the remaining seven sessions. Each participant was then given an instruction sheet detailing the procedure for completing the Internet sessions, which included the URL for the study's web page, the participant's login and password, and directions for accessing the chat rooms. Males were assigned the login "subject1login;" females were assigned the login "subject2login." When the female-female dyads were chatting, the second participant to enter the chat room was automatically called "subject1login_\#2" to differentiate between the chatters. Participants were also assigned a code number with which the experimenter could later identify their conversations, and they were given specific instructions as to the procedure to follow once in the chat room, in order to standardize the format between chat sessions.

After they completed their first face-to-face session with the experimenter, participants were partnered anonymously with another participant. None of the participants knew 
their partners' identities, and they were specifically asked not to volunteer or request identifying information during the chat sessions that might jeopardize their own or their partners' anonymity. At no time were partners allowed to communicate directly with one another except in the chat room, where their identities were disguised by the logins. All other communication was conducted through the experimenter. Participants had the same partner for the duration of the study.

The next step was to schedule participants for two Internet sessions. All scheduling was accomplished using email between the experimenter and participants, who all had email accounts prior to entering the study. Telephone calls were used as a last resort only when participants failed to respond to their emails. On the occasions when one or both of the participants in a dyad failed to report for a chat session, the session was rescheduled as soon as possible. Three couples were eliminated from the study because partners repeatedly failed to report to chat sessions, making completion of the study within the necessary timeframe impossible.

On the night before or the morning of the Internet sessions, one participant in each dyad was sent three discussion questions via email in order to give the participants direction during the chat sessions as well as to standardize the interactions. Each couple received the same sets of questions in the same sequence. The questions were intended to stimulate conversation; but, in order to avoid embarrassment or discomfort, they were not personal or objectionable in nature. Rather, participants were asked about their opinions and preferences (e.g., "If you could go out today and get any car, what kind of car would you buy? What color? What features?" and "Do you read your horoscope? How do you feel about astrology? Has a prediction ever come true for you?"). In the emails, the experimenter also reminded participants of the time the sessions were to occur and in which chat room they were meeting their partners. Those participants in each dyad who were not sent the discussion questions for a given session were sent emails informing them that their partners had been sent the discussion questions and also reminding them of the times and chat rooms for their sessions.
Participants began each session by typing their identification numbers and the date and time of the session to help the experimenter identify the transcripts later. Once both participants in a pair were present in the chat room, the participant with the discussion questions was supposed to ask the first question and to enter the time at which they began talking about the questions. It was therefore possible to determine how long participants talked about each question, although these data were not calculated for this study. The participants then discussed the question for as long as they wanted. They then followed the same procedure for the second and third questions.

After two Internet sessions, participants met with the experimenter again individually. At this second face-to-face interaction, they filled out the same questionnaires as during the initial session. Once both members of a dyad had met with the experimenter and completed the mid-test, the dyad was scheduled for three more Internet interactions in the same manner as before. The third, fourth, and fifth sessions were conducted using the same protocol. After they completed the final three Internet sessions, for a total of five for the study, participants met with the experimenter one last time and again completed the scales. At the end of the final face-to-face session, participants were debriefed fully.

\section{RESULTS}

First, the mean scores for each of the scales and subscales were calculated for the participant group as a whole. Table 1 shows the means scores for each scale and subscale for the pre-test, mid-test, and post-test. As predicted, the overall scores improved over the course of the study. Mean depression (CES-D) and loneliness (UCLA) scores declined significantly. At the same time, mean scores on three of the CHISEL subscales-belonging, tangible (perceived availability of material aid), and appraisal-increased over time, indicating that participants' perceptions of social support were elevated over the course of the study. Furthermore, self-esteem (as measured by the TSBI and CHISEL self-esteem inventory) scores improved during the study. 
Table 1. Descriptive Pre-Test, Mid-Test, and Post-Test Statistics by Scale/Subscale and F statistics

\begin{tabular}{|c|c|c|c|c|c|c|c|c|}
\hline \multirow[b]{2}{*}{ Scale } & \multicolumn{2}{|c|}{ Pre-Test } & \multicolumn{2}{|c|}{ Mid-Test } & \multicolumn{2}{|c|}{ Post-Test } & \multirow[b]{2}{*}{$d f$} & \multirow[b]{2}{*}{$F$} \\
\hline & $n$ & $M(S D)$ & $n$ & $M(S D)$ & $n$ & $M(S D)$ & & \\
\hline CES-D & 40 & $13.20(7.14)$ & 40 & $2.80(8.70)$ & 40 & $9.88(7.13)$ & 39 & $9.19^{b}$ \\
\hline TSBI & 39 & 88.05 (16.71) & 40 & 88.55 (17.74) & 40 & 92.35 (17.53) & 38 & $10.09 \mathrm{~b}$ \\
\hline UCLA & 39 & $34.38(9.15)$ & 39 & $32.13(8.49)$ & 40 & $30.75(8.37)$ & 38 & $17.79^{a}$ \\
\hline Appraisal & 39 & $11.36(0.96)$ & 40 & $11.48(0.82)$ & 39 & $11.72(0.56)$ & 38 & $6.62^{c}$ \\
\hline Belonging & 39 & $11.05(1.23)$ & 40 & $11.53(0.82)$ & 40 & $11.63(0.81)$ & 38 & $10.82^{b}$ \\
\hline Tangible & 40 & $10.53(1.06)$ & 40 & $11.60(0.81)$ & 40 & $11.63(1.00)$ & 39 & 138.79 \\
\hline $\begin{array}{l}\text { Self- } \\
\text { esteem }\end{array}$ & 37 & $10.59(1.79)$ & 40 & $10.65(1.78)$ & 37 & $10.78(1.65)$ & 36 & 1.09 \\
\hline
\end{tabular}

${ }^{\mathrm{a}} p<0.001$

$\mathrm{b}_{p}<0.01$.

$c_{p}<0.05$.

The $n$ values differ because not all participants responded to every item on each questionnaire. Scales with missing values were not calculated.

In order to determine whether the changes in individual scores over time were statistically significant, repeated measures analyses were performed for the entire participant group for each of the scales and subscales. Table 1 shows the $\underline{F}$ statistics for each of the scales/subscales. The repeated measures analyses of the CES-D and UCLA showed that the changes on both scales were statistically significant [CES-D: $F(1,39)=9.19, p<0.01$; UCLA: $F(1,38)=17.79$, $p<0.001]$. The same was true for three of the CHISEL subscales [appraisal: $F(1,38)=6.62$, $p<0.05$; belonging: $F(1,38)=10.82, p<0.01$; tangible: $F(1,39)=138.79, p<0.001]$. Although the self-esteem subscale scores did not change significantly $[F(1,36)=1.09, \mathrm{NS}]$, the changes in the TSBI were significant $[F(1,38)=10.09, p<$ $0.01]$. Taken together, the analyses support our prediction.

Given that these results were consistent with the more general hypothesis that Internet use would lead to improved depression, loneliness, self-esteem, and perceived social support scores, the analyses were computed again, this time controlling for gender. Table 2 shows the mean scores for each of the scales and subscales broken down by gender. The mean CES-D and UCLA scores showed similar downward trends for both males and females. The TSBI and CHISEL self-esteem subscale showed that both males and females registered higher self-esteem scores at post-test than at pre-test, although males' self-esteem subscale scores took a slight dip at mid-test. On each of the other three CHISEL subscales, the males' and females' scores rose similarly to the scores calculated for the group as a whole.

Next, each of the repeated measures analyses was computed again with gender added as a between-participants variable. Table 3 shows the $F$ statistics for these analyses. Contrary to the hypothesis, none of the interactions approached statistical significance, indicating that there were no noteworthy difference gender effects.

Graphing the mean pre-test, mid-test, and post-test scores for males and females on each of the scales / subscales showed that the males' and females' plots tended to be similar in shape or in point of convergence. However, they were dissimilar enough to warrant running another series of repeated measures analyses. This time, we compared pre-test means with mid-test means, and then we compared mid-test means with post-test means, in order to determine whether significant gender differences would appear that were not captured by our original analyses. Again, the gender interactions were nonsignificant for all of the scales and subscales. The $F$ statistics for these analyses are also presented in Table 3.

\section{DISCUSSION}

In recent years, two dominant lines of research on the Internet-user interaction have emerged. One focuses on the social and psychological effects of Internet use, and the other looks at gender differences in Internet use. So far, though, there is little crossover between 
Table 2. Descriptive Pre-Test, Mid-Test, and Post-Test Statistics BY SCALE/SUbSCALE AND GENDER

\begin{tabular}{|c|c|c|c|c|c|c|}
\hline \multirow[b]{2}{*}{ Scale } & \multicolumn{3}{|c|}{ Males } & \multicolumn{3}{|c|}{ Females } \\
\hline & $n$ & $M$ & $S D$ & $n$ & $M$ & $S D$ \\
\hline \multicolumn{7}{|l|}{ CES-D } \\
\hline Pre-test & 12 & 11.17 & 6.13 & 28 & 14.07 & 7.47 \\
\hline Mid-test & 12 & 10.92 & 7.22 & 28 & 13.61 & 9.27 \\
\hline Post-test & 12 & 7.67 & 5.02 & 28 & 10.82 & 7.75 \\
\hline \multicolumn{7}{|l|}{ TSBI } \\
\hline Pre-test & 12 & 92.67 & 13.20 & 27 & 86.00 & 17.90 \\
\hline Mid-test & 12 & 95.83 & 13.93 & 27 & 86.33 & 18.19 \\
\hline Post-test & 12 & 100.25 & 12.96 & 27 & 89.81 & 18.10 \\
\hline \multicolumn{7}{|l|}{ UCLA } \\
\hline Pre-test & 11 & 34.18 & 9.47 & 27 & 34.26 & 9.31 \\
\hline Mid-test & 11 & 32.45 & 9.08 & 27 & 32.04 & 8.57 \\
\hline Post-test & 11 & 29.73 & 9.88 & 27 & 31.48 & 8.07 \\
\hline \multicolumn{7}{|l|}{ Appraisal } \\
\hline Pre-test & 12 & 11.08 & 1.17 & 26 & 11.46 & 0.86 \\
\hline Mid-test & 12 & 11.58 & 0.52 & 26 & 11.46 & 0.91 \\
\hline Post-test & 12 & 11.58 & 0.67 & 26 & 11.77 & 0.51 \\
\hline \multicolumn{7}{|l|}{ Belonging } \\
\hline Pre-test & 12 & 11.00 & 1.35 & 27 & 11.07 & 1.21 \\
\hline Mid-test & 12 & 11.42 & 1.17 & 27 & 11.56 & 1.17 \\
\hline Post-test & 12 & 11.67 & 0.65 & 27 & 11.59 & 0.57 \\
\hline \multicolumn{7}{|l|}{ Tangible } \\
\hline Pre-test & 12 & 10.67 & 0.78 & 28 & 10.46 & 1.17 \\
\hline Mid-test & 12 & 11.67 & 0.89 & 28 & 11.57 & 0.79 \\
\hline Post-test & 12 & 11.67 & 0.89 & 28 & 11.61 & 1.07 \\
\hline \multicolumn{7}{|l|}{ Self-esteem } \\
\hline Pre-test & 11 & 10.91 & 1.38 & 23 & 10.30 & 2.01 \\
\hline Mid-test & 11 & 10.64 & 1.29 & 23 & 10.39 & 2.11 \\
\hline Post-test & 11 & 11.18 & 1.08 & 23 & 10.48 & 1.90 \\
\hline
\end{tabular}

the two. The goal of this study was to bridge these interests and examine how Internet use affects male and female users differently. Participants engaged in a series of synchronous chat sessions and at three intervals completed measures of depression, loneliness, selfesteem and perceived social support. We hy- pothesized that across the entire group of participants, loneliness and depression scores would decrease over the course of the study, while self-esteem and perceived social support was expected to increase. In line with current research, which has shown that women are more likely to be motivated to use the Internet

Table 3. F Statistics For the Repeated Measures Analyses by Scale/Subscale

\begin{tabular}{|c|c|c|c|c|c|c|c|c|c|}
\hline \multirow[b]{2}{*}{ Scale } & \multicolumn{3}{|c|}{ All changes } & \multicolumn{3}{|c|}{$\begin{array}{c}\text { From pre-test } \\
\text { to mid-test }\end{array}$} & \multicolumn{3}{|c|}{$\begin{array}{c}\text { From mid-test } \\
\text { to post-test }\end{array}$} \\
\hline & $F$ & $d f$ & Sig. & $F$ & $d f$ & Sig. & $F$ & $d f$ & Sig. \\
\hline CES-D & 0.01 & 36 & 0.92 & 0.01 & 38 & 0.93 & 0.04 & 38 & 0.84 \\
\hline TSBI & 1.24 & 37 & 0.27 & 1.07 & 37 & 0.31 & 0.13 & 38 & 0.72 \\
\hline UCLA & 0.97 & 36 & 0.33 & 0.10 & 36 & 0.75 & 1.86 & 37 & 0.18 \\
\hline Appraisal & 0.38 & 36 & 0.54 & 3.34 & 37 & 0.07 & 1.89 & 37 & 0.18 \\
\hline Belonging & 0.16 & 37 & 0.70 & 0.38 & 37 & 0.85 & 0.47 & 38 & 0.50 \\
\hline Tangible & 0.49 & 38 & 0.49 & 0.25 & 38 & 0.62 & 0.06 & 38 & 0.81 \\
\hline Self-esteem & 0.05 & 32 & 0.82 & 1.03 & 35 & 0.32 & 1.29 & 35 & 0.26 \\
\hline
\end{tabular}

Sig., significance. 
for interpersonal communication, we further hypothesized that the changes in scores would be somewhat greater for women. The first hypothesis proved correct. Loneliness and depression were significantly lower and selfesteem and perceived social support were significantly higher at post-test than they were at pre-test. However, contrary to our second hypothesis, gender differences did not approach significance.

In light of the pervasive belief that there are gender differences inherent in computer and Internet use, this total lack of gender differences is surprising. Of course, it is possible that despite the widespread belief that gender differences affect computer use, none actually exist. It is true that the existing literature is conflicting and inconclusive. However, more than 20 years of studies point to the existence of gender differences in anxiety, comfort, and experience with computers and now the Internet.

If anything, the lack of gender differences might be attributed to the population studied. The participants for this study were drawn from college undergraduates in the year 2000, a population likely to be among the more technologically adept and Internet savvy studied so far. Even assuming that prior research demonstrating gender differences was correct, computers and the Internet are so quickly becoming an integral and inescapable part of daily life that, as Morahan-Martin points out, surveys and studies quickly become outdated and less applicable. ${ }^{4}$ Hence, we might conclude that the lack of gender differences found in this study reflects a rapidly narrowing gender gap among younger generations.

Another possible explanation is methodological. Chatting was the chosen Internet application in this study primarily because chatting is clearly motivated by a desire to communicate, unlike email, which can be much more utilitarian. We hoped that it would be a gendered activity since women have been shown to use the Internet more for interpersonal communication and also to like using the Internet more for that purpose.7,10,12 However, two recent studies suggest that chatting is not gendered in the way email is gendered; one found that males actually chat more than females, ${ }^{3}$ while the other found no difference. ${ }^{9}$
Moreover, as Morahan-Martin and Sherman et al. point out, hostility is common and rarely sanctioned in chat rooms. ${ }^{3,26}$ According to these authors, this is a disincentive for women to participate in chat room discussions.

The gender effects we predicted were dependent largely on increased comfort among the female participants because of the interpersonal communication application. Also, the chat sessions were structured to control the environment somewhat. Sampling the recorded discussions showed that they were polite and sociable, even sometimes impersonal. Nonetheless, if the female participants had prior negative exposure to chatting, this could have negated potential effects. Thus, it is possible that we did not find the gender differences we expected not because the gender differences do not exist, but rather because chatting does not elicit them.

Another explanation that might be considered is that the generalizations drawn from earlier research-namely, that males are overall more comfortable with Internet use, but females are more apt to use the Internet for communication-are correct, and that these two effects cancelled each other out in the data. In that case, it might be easier to educe stronger gender effects using a "male" activity, such as playing interactive Internet games.

\section{FUTURE DIRECTIONS}

Because the Internet is becoming intertwined indelibly with daily life, it is important to understand how and why people use it. The Internet is a potential source of knowledge, information, and social interaction. Technological know-how is a must in higher education and in many realms of the job market. If females shy away from the Internet or feel discouraged from accessing it, this could lead to a serious educational and professional deficit among women. Thus, it is essential that we understand how females view the Internet, what draws them to email or other applications that are particularly popular among female users, and what deters them from logging on, in order to maximize the potential benefits of Internet use. On the other hand, if Internet use is 
detrimental to social and psychological health, future problems might be preventable. In particular, if it is true that males use the Internet more or in a more interactive way, they might be particularly vulnerable to harm.

As it stands now, there is little agreement among researchers about the reasons people use the Internet and how it affects them. The majority of the research conducted so far has been survey collection, and the empirical studies have yielded conflicting results. Little effort has been invested in applying established constructs to the realm of the Internet, although concepts such as self-handicapping, social comparison, and deindividuation might help explain why some people are more drawn to the Internet than others, why people become more or less lonely and depressed after using the Internet, and why people engage in behaviors such as flaming, for example. Any concept studied in the disciplines of communication, sociology, social psychology, etc., can be applied to this research because the Internet is truly a social technology.

The current study raises many questions about the nature of the Internet-user interaction. Clearly the results of this study run counter to a priori assumptions about gender differences in Internet use and the way the Internet affects users. What is unclear is whether these results are specific to the current methodology; specific to anonymous, synchronous chatting; or demonstrate the inaccuracy of our beliefs about the Internet. More research is needed to clarify the nature of the supposed gender differences, the effects of Internet use on social and psychological variables, and the particular circumstances that elicit the effects.

\section{REFERENCES}

1. McIlroy, D., Bunting, B., Tierney, K., et al. (2001). The relation of gender and background experience to self-reported computing anxieties and cognitions. Computers in Human Behavior 17:21-33.

2. Weiser, E.B. (2000). Gender differences in Internet use patterns and Internet application preferences: a two-sample comparison. CyberPsychology E Behavior 3:167-178.

3. Sherman, R.C., End, C., Kraan, E., et al. (2000). The Internet gender gap among college students: forgot- ten but not gone. CyberPsychology \& Behavior 3: 885-894.

4. Morahan-Martin, J. (1998). Males, females, and the Internet. In: Gackenbach, J., ed. Psychology and the Internet. San Diego: Academic Press, pp. 169-197.

5. Schumacher, P., \& Morahan-Martin, J. (2001). Gender, Internet and computer attitudes and experiences. Computers in Human Behavior 17:95-110.

6. Wolfradt, U., \& Doll, J. (2001). Motives of adolescents to use the Internet as a function of personality traits, personal and social factors. Lournal of Educational Computing Research 24:13-27.

7. Jackson, L.A., Ervin, K.S., Gardner, P.D., et al. (2001). Gender and the Internet: women communicating and men searching. Sex Roles 44:363-379.

8. Nielsen/ / NetRatings. (2002). Number of female Web surfers grows faster than overall Internet population, according to Nielsen/ / NetRatings [On-line]. Available: www.nielsen-netratings.com.

9. Odell, P.M., Korgen, K.O., Schumacher, P., et al. (2000). Internet use among female and male college students. CyberPsychology E Behavior 3:855-862.

10. Boneva, B., Kraut, R., \& Frohlich, D. (2001). Using email for personal relationships. American Behavioral Scientist 45:530-549.

11. Kraut, R., Patterson, M., Lundmark, V., et al. (1998). Internet paradox: a social technology that reduces social involvement and psychological well-being. American Psychologist 53:1017-1031.

12. Hamburger, Y.A., \& Ben-Artzi, E. (2000). The relationship between extraversion and neuroticism and the different uses of the Internet. Computers in Human Behavior 16:441-449.

13. Mannix, M., Locy, T., Clark, K., et al. (2000). The Web's dark side: In the shadow of cyberspace, an ordinary week is a frightening time. US News and World Report 129:36-45.

14. Grohol, J.M. (2000). Caught in the Net: how to recognize signs of Internet addiction and a winning strategy for recovery. Addiction 95:139-140.

15. Sanders, C.E., Field, T.M., Diego, M., et al. (2000). The relationship of Internet use to depression and social isolation among adolescents. Adolescence 35: 237-241.

16. Eastin, M.S., \& LaRose, R. (2000). Internet selfefficacy and the psychology of the digital divide. Journal of Computer-Mediated Communication [Online]. Available: www.ascusc.org/jcmc/vol6/ issue1/eastin.html.

17. Morahan-Martin, J., \& Schumacher, P. (2000). Incidence and correlates of pathological Internet use among college students. Computers in Human Behavior 16:13-29.

18. Griffiths, M. (1998). Internet addiction: does it really exist? In: Gackenbach, J., ed. Psychology and the Internet. San Diego: Academic Press, pp. 77-109.

19. Kiang, K. (2002). Addictions provoked by computer, Internet use. The Michigan Daily 29:1,7.

20. McKenna, K.Y.A., \& Bargh, J.A. (2000). Plan 9 from cyberspace: the implications of the Internet for per- 
sonality and social psychology. Personality and Social Psychology Review 4:57-75.

21. LaRose, R., Eastin, M.S., \& Gregg, J. (2001). Reformulating the Internet paradox: social cognitive explanations of Internet use and depression. Journal of Online Behavior [On-line]. Available: www.behavior.net/ JOB/v1n2/paradox.html.

22. Radloff, L.S. (1977). The CES-D Scale: a self-report depression scale for research in the general population. Applied Psychological Measurement 1:385-401.

23. Russell, D., Peplau, L., \& Cutrona, C.E. (1980). The Revised UCLA Loneliness Scale: concurrent and discriminant validity evidence. Journal of Personality and Social Psychology 39:472-480.

24. Helmreich, R., \& Stapp, J. (1974). Short forms of the Texas Social Behavior Inventory (TSBI), an objective measure of self-esteem. Bulletin of the Psychonomic Society 4:473-475.
25. Cohen, S., \& Hoberman, H. (1983). Positive events and social supports as buffers of life-change stress. Journal of Applied Social Psychology 13:99-125.

26. Morahan-Martin, J. (2000). Women and the Internet: promise and perils. CyberPsychology \& Behavior 3:683-691.

Address reprint requests to: Lindsay Shaw c/o Larry Gant University of Michigan 3780 School of Social Work Building 1080 S. University Ann Arbor, MI 48109

Email: 1hshaw@uclink.berkeley.edu 


\section{This article has been cited by:}

1. L. L. DeBar, J. Dickerson, G. Clarke, V. J. Stevens, C. Ritenbaugh, M. Aickin. 2009. Using a Website to Build Community and Enhance Outcomes in a Group, Multi-Component Intervention Promoting Healthy Diet and Exercise in Adolescents. Journal of Pediatric Psychology 34:5, 539-550. [CrossRef]

2. R. Fletcher, G. Vimpani, G. Russell, D. Keatinge. 2008. The evaluation of tailored and web-based information for new fathers. Child: Care, Health and Development 34:4, 439-446. [CrossRef]

3. 2008. Perceived Gender Based Stereotypes in Educational Technology Advertisements. Tech Trends 52:3, 46-52. [CrossRef]

4. Keum Seong Jang, Seon Young Hwang, Ja Yun Choi. 2008. Internet Addiction and Psychiatric Symptoms Among Korean Adolescents. Journal of School Health 78:3, 165-171. [CrossRef]

5. Neil Selwyn. 2007. Hi-tech = Guy-tech? An Exploration of Undergraduate Students' Gendered Perceptions of Information and Communication Technologies. Sex Roles 56:7-8, 525-536. [CrossRef]

6. L. Seymour, K. Nadasen. 2007. Web access for IT staff: a developing world perspective on web abuse. The Electronic Library 25:5, 543-557. [CrossRef]

7. Lynda Andrews, Geoffrey Kiel, Judy Drennan, Maree V. Boyle, Jay Weerawardena. 2007. Gendered perceptions of experiential value in using web-based retail channels. European Journal of Marketing 41:5/6, 640-658. [CrossRef]

8. Chad Raphael, Christine Bachen, Kathleen-M. Lynn, Jessica Baldwin-Philippi, Kristen A. McKee. 2006. Portrayals of Information and Communication Technology on World Wide Web Sites for Girls. Journal of Computer-Mediated Communication 11:3, 771-801. [CrossRef]

9. Susan E. Cook. 2004. NEW TECHNOLOGIES AND LANGUAGE CHANGE: Toward an Anthropology of Linguistic Frontiers. Annual Review of Anthropology 33:1, 103-115. [CrossRef]

10. Dr. Oxana Palesh , Kasey Saltzman, Cheryl Koopman . 2004. Internet Use and Attitudes Towards Illicit Internet Use Behavior in a Sample of Russian College StudentsInternet Use and Attitudes Towards Illicit Internet Use Behavior in a Sample of Russian College Students. CyberPsychology Behavior 7:5, 553-558. [Abstract] [PDF] [PDF Plus] 